\title{
Viral and fungal pathogens associated with Pneumolaelaps niutirani (Acari: Laelapidae): a mite found in diseased nests of Vespula wasps
}

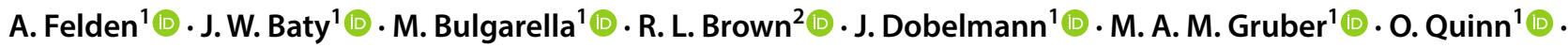 \\ P. J. Lester ${ }^{1}$ iD
}

Received: 14 June 2019 / Revised: 22 September 2019 / Accepted: 9 October 2019 / Published online: 8 November 2019

(C) International Union for the Study of Social Insects (IUSSI) 2019

\begin{abstract}
Introduced social wasps (Vespula spp.) are a pest in many parts of the world. Recently, a mite species (Pneumolaelaps niutirani) was described and associated with disease symptoms in wasps. The mite does not appear to directly parasitise the wasps, but has been observed in high abundance, feeding on exudates from the mouths of larvae. We investigated the viral and fungal pathogens community in these mites and wasps. We found known viruses including Moku virus in both wasps and mites. Moku virus replicated in mites, likely indicating parasitism. Deformed wing virus, commonly found in wasps, was also detected in mite samples. Furthermore, the presence of putative viral transcripts related to 38 distinct viruses, including seven viruses previously isolated from arthropods, indicated that there may be many more viruses associated with the mite that are potentially shared with Vespula wasps. We also found generalist entomopathogenic fungus Aspergillus to infect both mites and wasps. Twelve distinct Aspergillus species were observed, all of which were found in wasp larvae from nests displaying symptoms of disease, with only one species in larvae from apparently healthy nests. Aspergillus novofumigatus was the most common of these species observed in wasps. Six Aspergillus species, including A. novofumigatus were detected in mites. Aspergillus loads were significantly higher in larvae from diseased nests. Our exploratory study indicates that mites can harbour both viruses and fungi that infect wasps, providing avenues of research into biological control using mites as infection vectors.
\end{abstract}

Keywords Pathosphere $\cdot$ Fungi $\cdot$ Pneumolaelaps niutirani $\cdot$ Vespula vulgaris $\cdot$ Viruses

\section{Introduction}

Social wasps in the genus Vespula are an invasive pest of substantial importance in many countries around the world (Lester and Beggs 2019). They can reach extremely high densities in their introduced range and have the ability to disrupt ecosystems (Barlow et al. 2002; Lester et al. 2017). These wasps are associated with a variety of impacts on

Electronic supplementary material The online version of this article (https://doi.org/10.1007/s00040-019-00730-y) contains supplementary material, which is available to authorized users.

A. Felden

Antoine.Felden@vuw.ac.nz

1 Centre for Biodiversity and Restoration Ecology, School of Biological Sciences, Victoria University of Wellington, PO Box 600, Wellington 6012, New Zealand

2 Manaaki Whenua-Landcare Research, PO Box 69040, Lincoln 7640, New Zealand human health and economy, ranging from sting-related allergic reactions or accidents, to costs associated with pollination disruption, direct predation of honeybees and competition with native animals (MacIntyre and Hellstrom 2015; Lester and Beggs 2019).

Vespula wasps are afflicted by a range of diseases and pathogens. A literature review recorded a total of 50 fungal species, 12 bacteria, five to seven nematodes, four protozoans, and two viruses previously associated with Vespula (Rose et al., 1999). Since 1999, next generation sequencing techniques and PCR approaches have confirmed the presence of a wide range of microbial taxa that could be pathogenic. Viruses such as Kashmir bee virus (KBV) and Moku virus are common in wasps (Lester et al. 2015; Dobelmann et al. 2017; Quinn et al. 2018; Gruber et al. 2019), and it has been shown that viral loads were associated with increased immune response and lower fitness (Dobelmann et al. 2017). The viral pathogen community in Vespula spp. wasps appears to be influenced by the viral community in 
other insects such honey bees (a prey species for wasps), and indirectly by bee parasites such as those carried by parasitic Varroa destructor mites (Santamaria et al. 2018; Loope et al. 2019). In V. vulgaris, pathogen assemblage and pathogen networks show distinct properties within native and invaded ranges, but also among different individuals within ranges (Gruber et al. 2019). Furthermore, fungi such as Aspergillus spp. have been suggested to require weakened hosts to be pathogenic in insects (St. Leger et al. 2000). Altogether, these results suggest complex pathogen dynamics among interacting arthropod species as well as within individual hosts.

A mite species, Pneumolaelaps niutirani, has recently been discovered in nests of $V$. germanica (Fan et al., 2016). This mite has since been found associated with other hymenopterans including honeybees throughout New Zealand, as well as $V$. vulgaris in Belgium and the UK. The mite does not appear to directly parasitise the wasps, but has been observed feeding on exudates from the mouths of larvae (Fig. 1a, b). Wasp nests with large numbers of mites have been frequently observed to display symptoms of disease or diseases (R. Brown pers. obs.). Typically, 'diseased' wasp larvae in the early stages of infection frequently had obvious white masses $(<1 \mathrm{~mm}$ in diameter) under their cuticle (Fig. 1c). Larvae in later stages of infection turned grey and exhibited reduced movement, before dying. We hypothesised that mites could play a role in the spread and dynamics of this unknown disease. Alternatively, the unknown disease may be unrelated to the mites but might facilitate mite population growth.

Currently, it is just speculative that $P$. niutirani is host to a disease or diseases that afflict wasps. Viruses and entomopathogenic fungi such as Aspergillus spp. have been investigated in wasps and considered as candidates for biological control (Harris et al. 2000; Quinn et al. 2018). The aim of this study was to examine $P$. niutirani for viruses and other pathogens whose prevalence in wasp nests could be associated with the presence of mites. We sampled $P$. niutirani from $V$. vulgaris and $V$. germanica colonies from both their introduced range in New Zealand and native range in Europe. We used a combination of RNA-sequencing and RT-PCR to investigate whether these mites carry pathogens such as viruses that could be transmitted between wasps and mites. We also examined the pathogen community in a sample of wasps from a nest displaying both disease and a heavy mite infestation, and a second wasp nest that appeared healthy without any mites. Here, our goal was to produce a list of candidate pathogens that could contribute to the health decline of mite-infested wasp nests and be further investigated for biological control programmes.
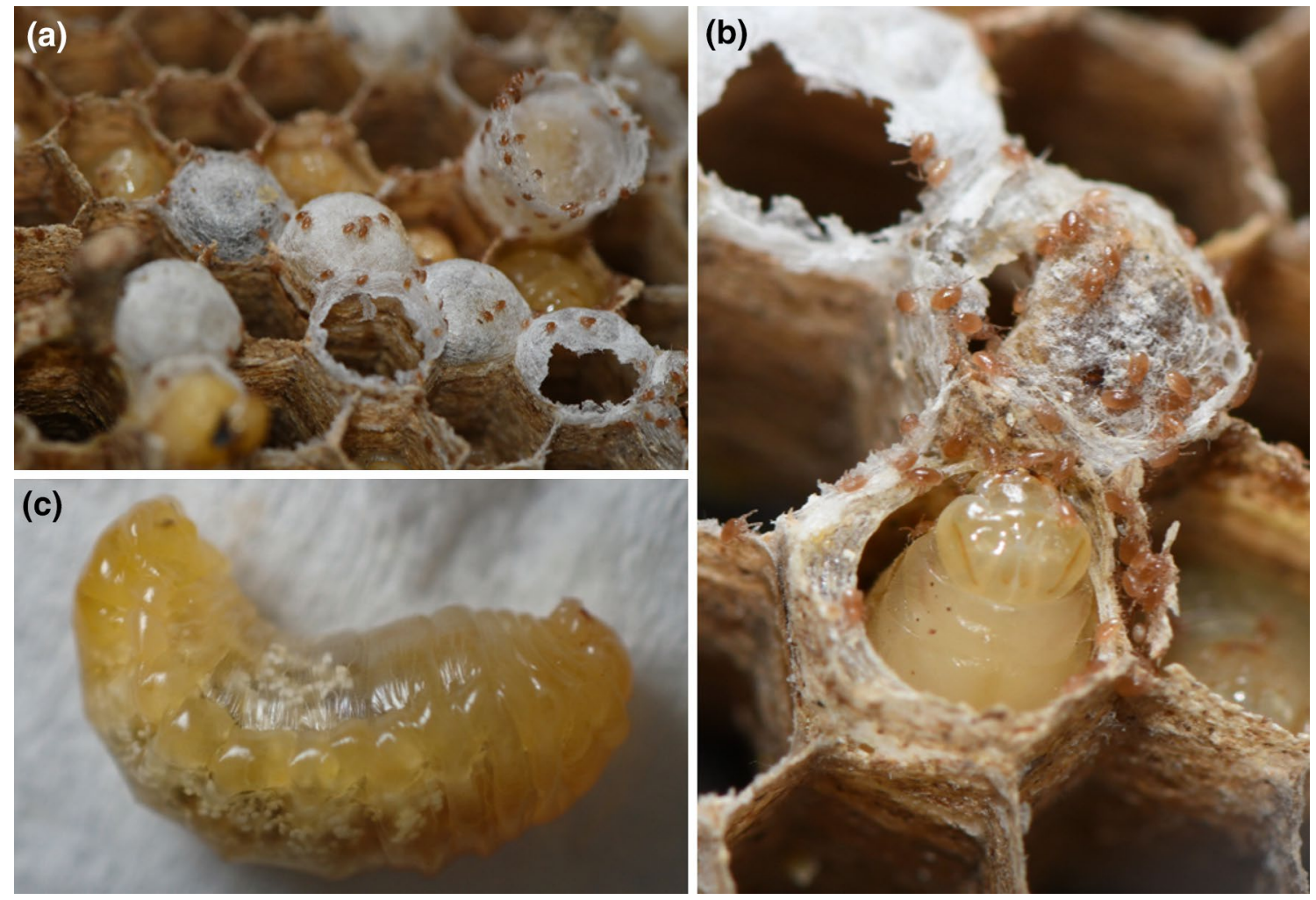

Fig. 1 a Pneumolaelaps niutirani on a wasp nest, $\mathbf{b}$ observed feeding on larvae exudates, $\mathbf{c}$ wasp larvae showing symptoms often associated with the presence of the mites. Images by Robert Brown 


\section{Materials and methods}

\section{RNA-Seq analysis}

Mites (P. niutirani) were collected from $V$. vulgaris wasps sampled from nests in the Canterbury region of New Zealand in April 2016 (Table 1). Approximately 100 mites from ten different nests were collected alive and snap frozen in liquid nitrogen, then stored at $-80{ }^{\circ} \mathrm{C}$ until use. We extracted total RNA from the pooled sample using the Direct-zol RNA MicroPrep Kit (Zymo Research, California, USA) following the manufacturer's protocol. RNA was eluted in $12 \mu \mathrm{l}$ of DEPC-treated water (Ambion, Texas, USA) and frozen immediately until shipped for sequencing.

Wasps (V. vulgaris) were sampled from two nests in Canterbury, New Zealand, in April 2016 (Table 1). One of the nests was apparently healthy and displayed no obvious signs of disease. The second nest was infected with mites, and wasp larvae present appeared to be diseased. The larvae in this diseased nest were discoloured and slow to respond to touch, although were clearly alive. The larvae were collected while alive and snap frozen in liquid nitrogen, then stored at $-80^{\circ} \mathrm{C}$ until use. We extracted RNA from whole larvae using a modified phenol/chloroform protocol. Briefly, we homogenised three replicates of single, whole larvae in a microcentrifuge tube with $1 \mathrm{~mL}$ of GENEzol reagent (Geneaid Biotech, Taiwan) and $5 \mu \mathrm{L}$ of $\beta$-mercaptoethanol (Sigma Aldrich, Michigan, USA) using a Precellys Evolution homogeniser (Bertin Instruments, France). RNA was eluted in $50 \mu \mathrm{L}$ of DEPC-treated water.

After extraction, RNA quantity and integrity were checked using a NanoRNA chip Bioanalyzer assay (Agilent Technologies, California, USA). The RNA extracts were stored in RNAStable ${ }^{\mathrm{TM}}$ (Biomatrica, Inc., California, USA) and sent for sequencing to Macrogen (Seoul, South Korea). Libraries were constructed using the Illumina TruSeq Stranded mRNA kit, with 100 bases-long paired-end reads sequencing on Illumina Hiseq 2500 (Illumina, San Diego, California, USA).

For bioinformatic analyses, we first aligned reads to an unpublished $V$. vulgaris draft genome with HISAT 2.1.0 (Kim et al. 2015) with default parameters to produce sample-specific BAM files. We then fed the BAM output into STRINGTIE 1.3.4 (Pertea et al. 2015) to generate GTF files, and generated a raw transcript counts matrix at the gene

Table 1 Pathogens identified using RT-PCR and RNA-Seq showing widespread presence of Aspergillus in wasps and mites, as well as potential for both mites and wasps to carry Moku virus, Deformed wing virus and Kashmir bee virus

\begin{tabular}{|c|c|c|c|c|c|c|c|c|c|}
\hline Species screened & Host/mite infested & Region & Pool size & Method & Moku virus & $\begin{array}{l}\text { Kashmir } \\
\text { bee virus }\end{array}$ & $\begin{array}{l}\text { Deformed } \\
\text { wing virus }\end{array}$ & $\begin{array}{l}\text { Nosema } \\
\text { vespula }\end{array}$ & $\begin{array}{l}\text { Asper- } \\
\text { gillus } \\
\text { spp. }\end{array}$ \\
\hline \multirow[t]{7}{*}{ P. niutirani } & V. germanica & Belgium $^{a}$ & 40 mites & RT-PCR & - & - & - & - & + \\
\hline & V. vulgaris & Belgium $^{\mathrm{b}}$ & 20 mites & & - & - & - & - & + \\
\hline & V. vulgaris & Belgium $^{c}$ & 25 mites & & - & - & - & - & + \\
\hline & V. vulgaris & United Kingdom $^{\mathrm{d}}$ & 20 mites & & + & - & - & - & + \\
\hline & V. germanica & Belgium $^{a}$ & 15 mites & & - & - & - & - & + \\
\hline & V. vulgaris & New Zealand ${ }^{\mathrm{e}}$ & Ten mites & & - & - & + & - & + \\
\hline & V. vulgaris & New Zealand ${ }^{\mathrm{e}}$ & 100 mites & RNA-Seq & + & - & - & - & + \\
\hline \multirow[t]{10}{*}{ V. vulgaris } & Mite-infested & New Zealand ${ }^{\mathrm{e}}$ & One larva & RT-PCR & - & - & - & - & + \\
\hline & & & One adult & & - & - & - & - & + \\
\hline & Mite-free & New Zealand ${ }^{\mathrm{e}}$ & One larva & & - & - & - & - & - \\
\hline & & & One adult & & - & - & - & - & + \\
\hline & Mite-free & New Zealand ${ }^{\mathrm{e}}$ & One larva & RNA-Seq & + & + & + & - & + \\
\hline & & & One larva & & + & + & + & - & + \\
\hline & & & One larva & & - & + & - & - & + \\
\hline & Mite-infested & New Zealand ${ }^{\mathrm{e}}$ & One larva & & + & + & - & - & + \\
\hline & & & One larva & & + & + & - & - & + \\
\hline & & & One larva & & + & + & - & - & + \\
\hline
\end{tabular}

Positive results are indicated with "+”, and absence of detection is indicated by "-". RNA-Seq results are partial and only given for pathogens screened with PCR, see full RNA-Seq results in Tables S2-S7

Samples from Belgium were collected in ${ }^{\mathrm{a}}$ Wesperlaar $(50.9593,4.6390),{ }^{\mathrm{b}}$ Lubbek $(50.8825,4.8372)$ and ${ }^{\mathrm{c}}$ Sint-Joris Weert (50.8043, 4.6517). Samples from the United Kingdom were collected in ${ }^{\mathrm{d}}$ Godalming $(51.1636,-0.5828)$ and samples from New Zealand were collected in ${ }^{\mathrm{e}}$ Little River, Canterbury $(-43.7597,172.8075)$ 
level using the authors' prepDE.py script. We imported the raw counts matrix into R 3.5.1 as a DGEList object using the edgeR 3.22.3 (Robinson et al. 2010), and computed $V$. vulgaris library size for each sample for downstream normalisation of viral loads.

Reads that did not align to the $V$. vulgaris genome were de novo assembled using TRINITY 2.3.2 (Haas et al. 2013) with default parameters. We quantified assembled transcript expression within Trinity using eXpress 1.5.1 (Roberts and Pachter 2012), yielding a TMM-normalised transcripts per million (TPM) matrix of assembled transcripts. We then used DIAMOND 0.9.24 (Buchfink et al. 2015) to run protein homology searches in the NCBI viral and fungi protein databases (downloaded February 1st and May 20th 2019, respectively), using a $e$-value cut-off of $10^{-5}$. To minimise false-positives, we discarded alignments that were less than 300 bases long (i.e., 100 amino acids). From the filtered DIAMOND output, we selected a single best hit per assembled transcript based on the highest bitscore. Queries that returned more than $95 \%$ amino acid identity were deemed as confident annotations, while queries that returned between 50 and $95 \%$ identity were listed separately, as putative viral sequences. To compute viral loads, we summed TPM values for all genes belonging to each identified virus and used the wasp reads library sizes to normalise viral loads to host tissue among samples. For putative viruses, low or variable sequence identity of the assembled transcripts to published reference sequences may indicate uncertain annotation to known viral taxa, and the transcripts could instead belong to unknown viruses. Therefore, we did not analyse viral loads for putative viruses and only reported presence/absence. Transcript quantification via RNA-Seq was confirmed via RT-qPCR using the TaqMan array qPCR methods described in Loope et al. (2019). All the computationally demanding analyses (i.e., alignments, assembly and DIAMOND searches) were run on Rāpoi, Victoria University of Wellington's High Performance Computer, and the rest using R 3.5.1 "Feather Spray".

\section{RT-PCR analysis}

This study focused on the $P$. niutirani/V. vulgaris system in New Zealand using RNA-Seq. We complemented such approach with RT-PCR screening of two mite samples from $V$. germanica nests collected in Belgium in September 2018 , four mite samples from native $V$. vulgaris nests (one from the United Kingdom and three from Belgium collected between July and September 2018) and one sample from an invasive $V$. vulgaris nest collected in New Zealand in February 2018 (Table 1). Mite RNA was extracted from pooled samples using the Direct-zol RNA MicroPrep Kit (Zymo Research, California, USA). We also extracted total RNA from four $V$. vulgaris wasps collected in New Zealand in February 2018 (one adult and one larva in both a healthy and a diseased nest; Table 1) using the modified chloroform protocol described above. We then reversed transcribed mite and wasp RNA following the qScript cDNA Supermix protocol (Quanta Biosciences, Massachusetts, USA). PCR was used to screen for five different pathogens: Moku virus, KBV, Deformed wing virus (DWV), Aspergillus spp. and Nosema vespula. PCR cycling conditions and primer sequences are provided in Table $\mathrm{S} 1$. Each locus was amplified in a $15-\mu \mathrm{L}$ PCR reaction containing $1 \mu \mathrm{L}$ cDNA, $1 \mu \mathrm{M}$ forward primer, $1 \mu \mathrm{M}$ reverse primer, water and $7.5 \mu \mathrm{L}$ MyTaq DNA polymerase Mix (Bioline, London, UK). Cycling conditions were: $5 \mathrm{~min}$ at $95^{\circ} \mathrm{C} ; 35-40$ cycles of $30 \mathrm{~s}$ at $95^{\circ} \mathrm{C}, 30 \mathrm{~s}$ at the annealing temperature (Table S1), and $45 \mathrm{~s}$ at $72^{\circ} \mathrm{C}$; followed by a final extension of $10 \mathrm{~min}$ at $72^{\circ} \mathrm{C}$. We included a positive control and a negative control in each PCR. PCR products were visualised on an agarose gel. Where PCR produced clear bands, products were treated with exonuclease-I and shrimp alkaline phosphatase (New England Biolabs, Massachusetts, USA) and Sanger sequenced on an ABI3730 DNA Analyzer (Massey Genome Services, Massey University, Palmerston North, New Zealand). Sequence base-calls were checked by eye using Geneious v.10.2.3 (Kearse et al. 2012). We used the Megablast program within Geneious to search against the nucleotide database in NCBI GenBank. Gene identifications were assigned to genes on the database based on highest sequence identity (>97\%).

We investigated Moku virus replication using strand specific RT-PCR to detect the negative viral strand (Yue and Genersch 2005). Approximately 100 ng RNA was reverse transcribed using the Superscript IV first strand synthesis system (Invitrogen, California, USA) and a primer targeting the negative strand of Moku virus (Garigliany et al. 2019) tagged with a short sequence that shows no similarity with any known invertebrate sequence or insect virus (Table S1; Yue and Genersch 2005). The PCR following this step was carried out with only the tag sequence and a virus-specific primer which ensures that only cDNA derived from the strand specific RT was amplified (de Miranda et al. 2013). To avoid false-positive detection, remaining RNA and tagged primer were digested prior to PCR using $2 \mathrm{U}$ RNase H (Invitrogen, California, USA) and $10 \mathrm{U}$ exonuclease-I (Thermo Scientific, Massachusetts, USA), respectively, following the manufacturer's instructions. PCR was performed using MyTaq ${ }^{\mathrm{TM}}$ Red Mix (Bioline, London, UK) at $55{ }^{\circ} \mathrm{C}$ annealing temperature. PCR products were run on a $2 \%$ agarose gel and sent to Macrogen Inc. (Seoul, South Korea) for sequencing in order to confirm amplification of the expected product and thus infer replication. 


\section{Results}

\section{RNA-Seq analysis}

The RNA-Seq analysis identified two virus species with high confidence: Moku virus and KBV (Table S2). Moku virus was found in both wasp larvae and mites. Interestingly, Moku virus transcripts were found in large quantities in mites (Table 2). KBV was only detected in wasp larvae libraries, and we did not find significant differences in viral loads between the healthy and diseased nests for Moku virus $\left(X^{2}=1.333, d f=1, p=0.248\right.$, Fig. $\left.2 \mathrm{a}\right)$ or KBV $\left(X^{2}=0.048, d f=1, p=0.827\right.$, Fig. $2 b$; but note discordant RT-qPCR results, Figure S1a and S1c). In addition to Moku virus and KBV, we found a large number of putative virus transcripts that displayed sequence similarities with known viruses, ranging from 50 to $95 \%$ identity for alignments longer than 100 amino acids. We report the summarised DIAMOND output separately for transcripts matching viruses known to infect arthropods (Table S3) and other taxa (Table S4).

In addition to Moku virus, we found six putative viruses known to infect arthropods that were shared between wasps and mites, i.e., Hunei picorna-like virus 15, Helicoverpa zea nudivirus 2, Diadromus pulchellus ascovirus 4a, Epinotia aporema granulovirus, Lymantria dispar multiple nucleopolyhedrovirus and Spodoptera frugiperda multiple nucleopolyhedrovirus (Fig. 3a, Table S3). We found that 38 (37\%) of all the putative viruses discovered were shared between mites and wasps (Fig. 3b, Tables S3, S4). Larvae from diseased and healthy nests shared $20(61 \%)$ of the putative viruses likely to infect arthropods, and $65(76 \%)$ of all the putative viruses found in wasp libraries only (Fig. 3a, b).

Overall, we found 41 fungus species across libraries, ranging from known entomopathogens to species first

Table 2 Viruses identified in the RNA-Seq data with high confidence, i.e., transcripts larger than 300 bases long and with amino acid identity $>95 \%$

\begin{tabular}{|c|c|c|c|c|c|c|c|}
\hline \multirow[t]{2}{*}{ Virus } & \multicolumn{3}{|c|}{ Healthy wasps } & \multicolumn{3}{|c|}{ Diseased wasps } & \multirow{2}{*}{$\begin{array}{l}\text { Mites } \\
\text { Unscaled load }\end{array}$} \\
\hline & Mean & d (range) & $\bar{n}$ & Mean & d (range) & $\bar{n}$ & \\
\hline Moku virus & 0.368 & $(0.359-0.377)$ & 2 & 0.134 & $(0.007-0.375)$ & 3 & 12,578 \\
\hline Kashmir bee virus & 7.586 & $(2.205-17.158)$ & 3 & 5.648 & $(0.731-8.231)$ & 3 & - \\
\hline
\end{tabular}

Viral loads are expressed as the sum of TMM-normalised TPM (transcript per million) counts for all transcripts assigned to a virus. Viral TPM counts in wasps were scaled to the respective wasp library size, but viral loads in mites are presented unscaled. The mean load estimates are only calculated from samples in which the virus was detected, i.e., values of 0 were excluded from the estimates

(a) Moku virus

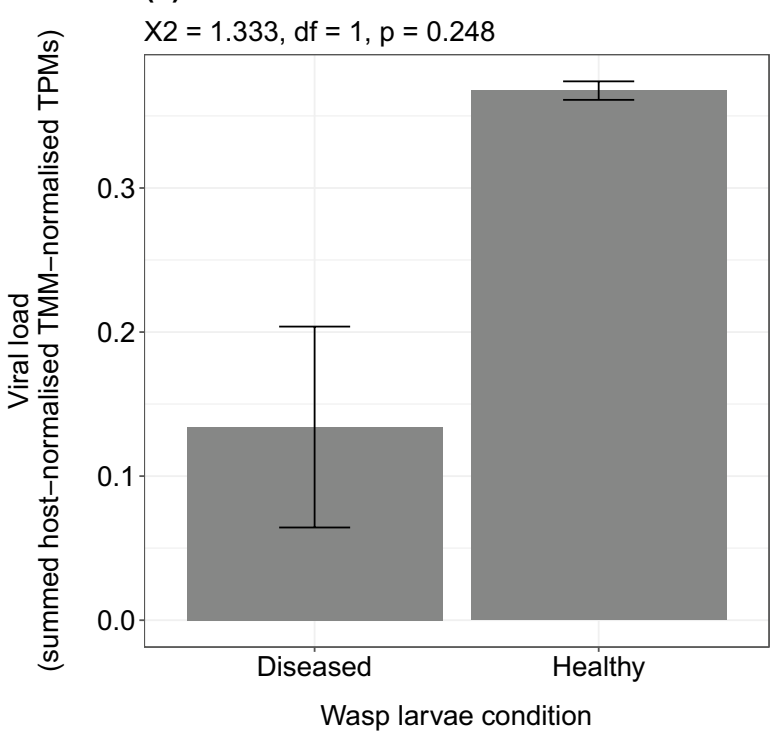

(b) Kashmir bee virus

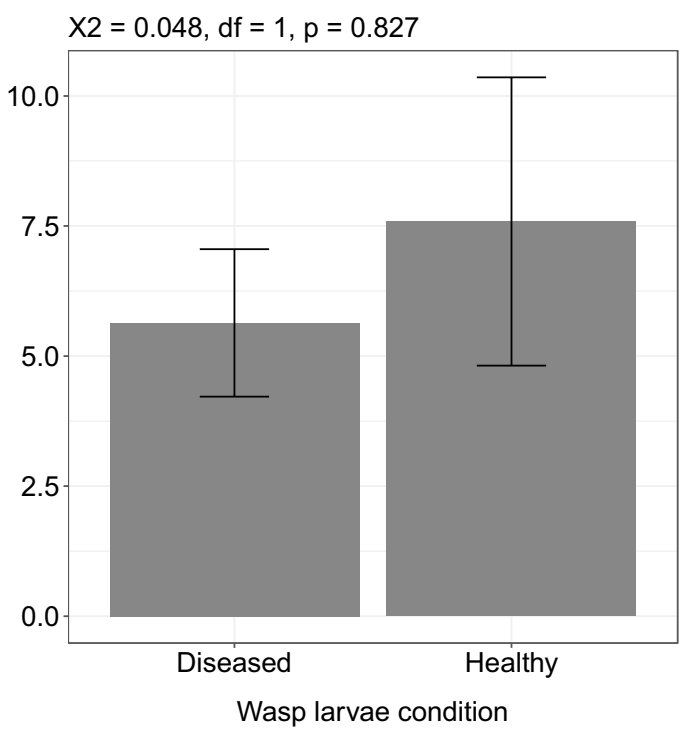

Fig. 2 Transcript quantification for a Moku virus and b Kashmir bee virus showing similar mean viral loads between healthy and diseased Vespula vulgaris larvae. Viral loads were computed as the sum of transcript per million (TPM) for all transcripts that matched viral genes with high confidence (transcripts longer than 300 bases for each virus). Raw counts were first TMM-normalised, and subsequently normalised to the number of Vespula vulgaris transcripts (see data in Table 2). Error bars indicate the standard error of the means 


\section{(a) Putative viruses} infecting arthropods

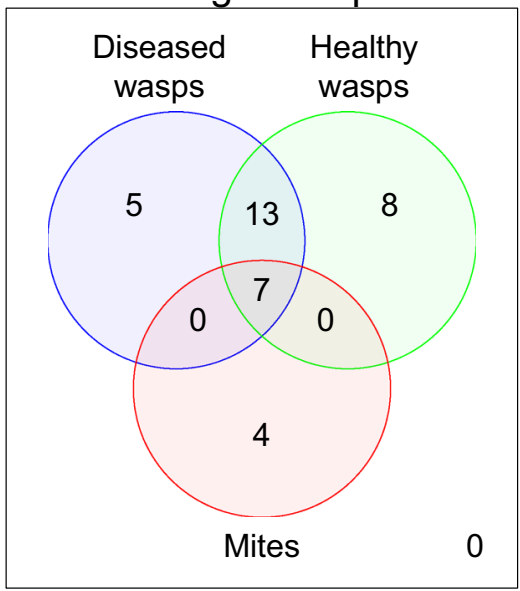

Fig. 3 Venn diagram showing the number of putative viruses shared among healthy wasps, diseased wasps and mites for a putative viruses infecting arthropods and $\mathbf{b}$ putative viruses infecting other taxa. Putative viruses were characterised by assembled transcripts longer than 100 amino acids with $>50 \%$ identity. Data for putative viruses infect-

isolated from the environment, plant-disease causing agents, or human pathogens (Table S5). Interestingly, the majority of taxa (i.e., 37/41) were detected in diseased larvae libraries, and only 18 in healthy larvae (Fig. 4a). We identified 12 distinct Aspergillus species in our dataset, all of which were found in diseased wasp larvae samples and only one species in healthy samples. Six Aspergillus species, including A. (b) Putative viruses

infecting other life forms

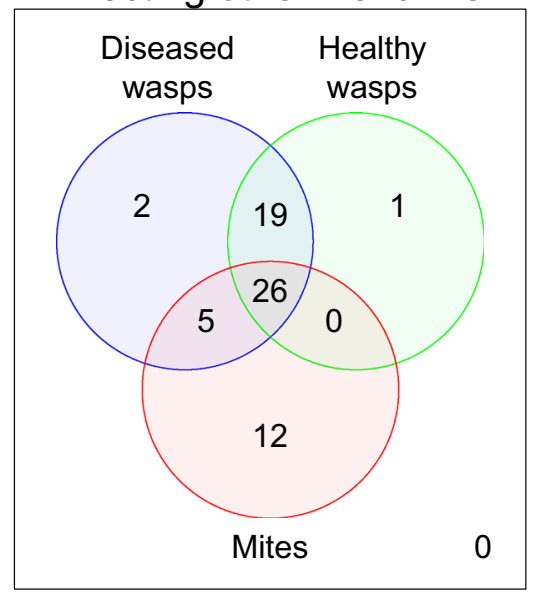

ing arthropods also includes viruses identified with high confidence, i.e., Moku virus and Kashmir bee virus. A full list of the putative viruses with summarised DIAMOND output identifying putative viruses is given in Tables $\mathrm{S} 2$ and $\mathrm{S} 3$

novofumigatus found in healthy larvae, were also detected in mites. Overall, Aspergillus loads were significantly higher in larvae from diseased nests $\left(X^{2}=2.333, d f=1, p<0.001\right.$; Fig. 4b, Table 3; confirmed via RT-qPCR, Figures S1b and S1d), and this trend was also found for most other fungi (Table 3). The entomopathogen Metarhizium robertsii was found in diseased larvae and mites, but not in healthy larvae. (a) Fungi shared between wasps

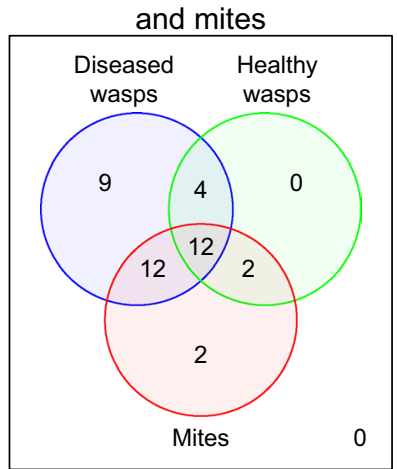

(b) Overall Aspergillus load

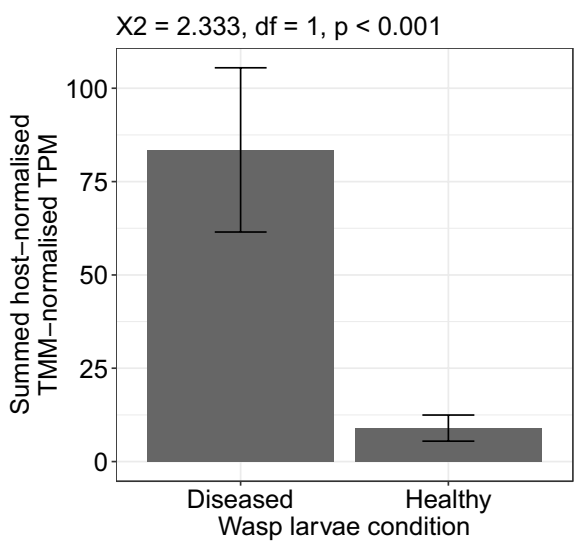

higher Aspergillus load in diseased compared to healthy larvae. Fungal loads were computed as the sum of transcript per million (TPM) for all transcripts that matched fungal genes with high confidence (transcripts longer than 300 bases that have at least 95\% amino acid identity to a given fungus). Raw counts were first TMM-normalised, and subsequently normalised to the number of Vespula spp. transcripts. Error bars indicate the standard error of the means 
Table 3 Fungi identified in the RNA-Seq data with high confidence, i.e., transcripts larger than 300 bases long and with amino acid identity $>95 \%$

\begin{tabular}{|c|c|c|c|c|c|c|c|}
\hline \multirow{3}{*}{$\begin{array}{l}\text { Fungus species } \\
\text { Aspergillus aculeatus }\end{array}$} & \multicolumn{3}{|c|}{ Healthy wasps } & \multicolumn{3}{|c|}{ Diseased wasps } & \multirow{3}{*}{$\begin{array}{l}\text { Mites } \\
\text { Unscaled load } \\
1.226\end{array}$} \\
\hline & \multicolumn{2}{|c|}{ Mean load (range) } & \multirow{2}{*}{$\frac{n}{3}$} & \multicolumn{2}{|c|}{ Mean load (range) } & \multirow{2}{*}{$\frac{\bar{n}}{0}$} & \\
\hline & 5.607 & $(0.786-10.679)$ & & - & - & & \\
\hline Aspergillus bombycis & 0.766 & - & 1 & - & - & 0 & - \\
\hline Aspergillus fischeri & 4.789 & $(1.161-9.813)$ & 3 & - & - & 0 & 0.595 \\
\hline Aspergillus flavus & 1.014 & $(0.174-1.854)$ & 2 & - & - & 0 & - \\
\hline Aspergillus glaucus & 2.271 & $(1.936-2.606)$ & 2 & - & - & 0 & 0.854 \\
\hline Aspergillus heteromorphus & 0.760 & $(0.535-0.984)$ & 2 & - & - & 0 & - \\
\hline Aspergillus ibericus & 0.248 & $(0.098-0.534)$ & 3 & - & - & 0 & - \\
\hline Aspergillus mulundensis & 0.413 & $(0.300-0.546)$ & 3 & - & - & 0 & - \\
\hline Aspergillus niger & 5.759 & $(1.150-12.178)$ & 3 & - & - & 0 & 1.058 \\
\hline Aspergillus novofumigatus & 63.111 & $(9.881-127.59)$ & 3 & 8.965 & $1.830-21.011$ & 3 & 11.258 \\
\hline Aspergillus steynii & 0.515 & $(0.379-0.652)$ & 2 & - & - & 0 & - \\
\hline Aspergillus terreus & 0.416 & $(0.184-0.648)$ & 2 & - & - & 0 & 0.302 \\
\hline Aureobasidium subglaciale & 4.093 & $(0.688-6.266)$ & 3 & - & - & 0 & 3.435 \\
\hline Babjeviella inositovora & 0.489 & - & 1 & 10.863 & 0.489 & 1 & - \\
\hline Batrachochytrium dendrobatidis & 900.649 & $(775.631-974.587)$ & 3 & 2960.281 & $1067.760-6724.946$ & 3 & 313.253 \\
\hline Byssochlamys spectabilis & 0.422 & $(0.248-0.596)$ & 2 & - & - & 0 & - \\
\hline Candida albicans & - & - & 0 & 3.452 & 3.452 & 1 & 0.392 \\
\hline Debaryomyces fabryi & 0.782 & $(0.240-1.308)$ & 3 & 16.236 & $0.270-48.170$ & 3 & 3.253 \\
\hline Debaryomyces hansenii & 0.519 & $(0.496-0.541)$ & 2 & 4.610 & 0.496 & 1 & 0.856 \\
\hline Eremothecium gossypii & 0.401 & $(0.140-0.662)$ & 2 & - & - & 0 & - \\
\hline Hyphopichia burtonii & 0.119 & - & 1 & 3.372 & 0.119 & 1 & 0.563 \\
\hline Metarhizium robertsii & 0.732 & $(0.094-1.113)$ & 3 & - & - & 0 & 0.236 \\
\hline Metschnikowia bicuspidata & 2.114 & $(0.258-3.970)$ & 2 & 51.609 & $0.220-102.996$ & 2 & 0.129 \\
\hline Meyerozyma guilliermondii & 0.223 & $(0.218-0.228)$ & 2 & 0.620 & 0.228 & 1 & 2.036 \\
\hline Moesziomyces antarcticus & 89.468 & $(82.740-95.1)$ & 3 & 96.709 & $86.420-115.839$ & 3 & - \\
\hline Paracoccidioides brasiliensis & 0.362 & $(0.286-0.437)$ & 2 & - & - & 0 & - \\
\hline Penicilliopsis zonata & 1.120 & $(0.527-1.713)$ & 2 & - & - & 0 & 0.198 \\
\hline Penicillium arizonense & 131.577 & $(16.958-226.106)$ & 3 & 0.083 & $0.030-0.137$ & 3 & 31.724 \\
\hline Penicillium digitatum & 157.717 & $(22.653-301.375)$ & 3 & 0.298 & $0.010-0.822$ & 3 & 300.586 \\
\hline Penicillium expansum & 116.509 & $(14.095-216.184)$ & 3 & 0.523 & 119.249 & 1 & 26.922 \\
\hline Penicillium rubens & 66.872 & $(8.064-117.768)$ & 3 & 0.979 & 74.784 & 1 & 16.882 \\
\hline Phycomyces blakesleeanus & 14.155 & $(12.475-15.388)$ & 3 & 113.292 & $15.940-306.304$ & 3 & - \\
\hline Pneumocystis jirovecii & - & - & 0 & - & - & 0 & 338.533 \\
\hline Rasamsonia emersonii & 4.763 & $(0.760-7.278)$ & 3 & - & - & 0 & 5.152 \\
\hline Rhizophagus irregularis & 0.029 & - & 1 & - & - & 0 & 710.217 \\
\hline Scheffersomyces stipitis & - & - & 0 & 0.039 & 0.039 & 1 & 0.904 \\
\hline Spizellomyces punctatus & 5243.08 & $(3653.690-6156.243)$ & 3 & 2917.206 & $1495.890-3852.615$ & 3 & 1767.728 \\
\hline Trichosporon asahii var. asahii & 0.022 & - & 1 & - & - & 0 & 255.383 \\
\hline Vavraia culicis subsp. floridensis & 12.901 & $(0.610-31.235)$ & 3 & 1.029 & $0.980-1.075$ & 2 & - \\
\hline Verticillium dahliae & 0.484 & $(0.434-0.534)$ & 2 & - & - & 0 & 0.192 \\
\hline Wallemia mellicola & - & - & 0 & - & - & 0 & 13.910 \\
\hline
\end{tabular}

Fungal loads are expressed as the sum of TMM-normalised transcript per million (TPM) counts for all transcripts assigned to a fungus species. Fungal TPM counts in wasps were scaled to the respective wasp library size, but fungal loads in mites are presented unscaled. The average abundance estimates are only from samples in which the fungus was detected, i.e., values of 0 were excluded from the average estimates. Fungi shared between wasps and mites are indicated in bold 
We also found Vavraia culicis, a microsporidium known to infect both mosquitos (Andreadis 2007) and V. vulgaris (Quinn et al., 2018), in both healthy and diseased wasp larvae but not mites.

\section{RT-PCR analysis}

In contrast with the RNA-Seq data, we found no evidence of Moku virus or KBV in the wasp samples screened using RT-PCR, but using this approach we detected Moku virus in one mite sample from the United Kingdom (Table 1), in which viral replication was confirmed. Only a mite sample collected in New Zealand carried DWV. In addition, Aspergillus spp. were present in all six mite samples and three of the four wasp samples screened via RT-PCR. Consistently with the RNA-Seq data, the wasp pathogen Nosema vespula (Solter et al., 2012) was not found in any of the four wasp or six mite samples screened.

\section{Discussion}

We investigated microbes associated with an unknown disease afflicting Vespula wasp nests in the presence of the newly described mite $P$. niutirani in order to scope out the possibility that mites may be associated with specific pathogens and facilitate health decline of invasive wasps. We show that the mites can carry infectious wasp viruses such as Moku virus, and also shared a substantial amount of putative viral transcripts with wasp larvae. Furthermore, our results indicate that fungi were more diverse and abundant in diseased wasp nests, including entomopathogenic taxa such as Aspergillus or Metharizhium that were also detected in mites.

Moku virus was first described from the invasive social wasp Vespula pensylvanica in 2016 (Mordecai et al. 2016). This Iflavirus is closely related to the Slow bee paralysis virus (SBPV). We found the Moku virus in both healthy and diseased wasps, which confirmed previous records (Quinn et al. 2018). Mordecai et al. (2016) also observed this virus in honeybees and their parasitic mite Varroa destructor. They suggested that the Moku virus is likely to infect a range of other hymenopteran and Acari hosts, which is supported by our results in P. niutirani and $V$. vulgaris larvae. However, negative RT-PCR results for Moku virus may indicate that it is not present in all wasps. Interestingly, Moku virus was present in large quantities in mites and was also shown to replicate in both wasps, suggesting the potential for spillover between the two species.

We also found evidence of KBV infecting wasp larvae using the RNA-Seq approach, but not RT-PCR, which suggests that similarly to Moku virus, $\mathrm{KBV}$ is not present in all wasps. KBV is a well-known honeybee pathogen that was also shown to replicate in wasps (Dobelmann et al. 2017) and Varroa mites (Chen et al. 2004). However, here we did not find evidence for the presence of KBV in mites using neither RNA-Seq nor RT-PCR, which may suggest that not all viruses can be shared between wasps and mites, but it could also be due to our small sample sizes. DWV, which also replicates in wasps and has been described from species such as Argentine ants (Levitt et al. 2013; Sébastien et al. 2015), was found in one mite sample using RT-PCR. Only one DWV transcript was assembled from RNA-Seq data and was only detected in the healthy wasp larvae, which provide limited evidence for possible DWV transmission between wasps and mites. Furthermore, limited extraction volumes did not allow us to test for DWV replication in mites.

Although we sampled wasps from only two nests, we found a remarkably high number of co-infecting putative viruses in our samples. However, the true viral species richness in our samples might be lower than reported, as putative assembled viral transcripts assigned to different viruses with low amino acid identity may actually originate from the same viruses or other taxa. Furthermore, RNASeq assemblies can erroneously produce chimeric viruses (e.g., Gruber et al. 2017), which might also affect transcript quantification and explain discrepancies between RT-qPCR and RNA-Seq. Nevertheless, the putative viral transcripts we found in wasps and mites were assigned to viruses spanning across at least 23 viral families, and at least eight different virus families likely to infect arthropods, indicating a possible substantial viral diversity. Many putative viruses were shared between mites and wasps, which supports the view of a 'pathosphere' encompassing multiple host species, consistent with intricate disease dynamics within arthropod communities (Rigaud et al. 2010). Pneumolaelaps niutirani can also be found in bee hives (Fan et al. 2016), and further investigation should resolve the effects of the mite on hive health, and whether its use as a biological control agent for wasps might result in adverse effects in honeybees, either through direct interaction or pathogen spillover.

The majority of putative viruses were shared between diseased and healthy larvae, perhaps indicating that those viruses did not actively infect wasps (e.g., detection from crop contents) or play a major role in an association with mites and the disease symptoms we observed. Virus replication and pathogenicity in bees is driven by a multitude of factors including nutrition, habitat or host microbiome (McMenamin et al. 2016). The high diversity of putative viruses in our samples may therefore reflect asymptomatic or covert viral infections in wasps, commonly reported in well-studied bee viruses (Grozinger and Flenniken 2019). Alternatively, instead of being attributable to a single pathogen, disease symptoms may be associated with the pathogen community, as pathogen networks might be key in understanding disease dynamics in wasps (Gruber et al. 2019). 
We found higher fungal diversity and loads in diseased compared to healthy larvae, and a majority of these fungal taxa were shared with mites. Aspergillus was a prevalent genus found in diseased nests and mites, and has been reported previously in Acari mites. Hay et al. (1993) described how this fungus might be mutualistic to its host dust mites (Dermatophagoides pteronyssinus) by providing micronutrients, although increasing fungal infections also reduced mite survival, development and fecundity. Aspergillus flavus has been previously identified as a wasp pathogen in New Zealand (Glare et al. 1996), and Aspergillus spp. are also known to cause the larval disease stonebrood in honeybees (Schwarz et al. 2015). Aspergillus spp. are considered to be opportunistic and generalist pathogens that may require weakened or wounded hosts to become abundant (St. Leger et al. 2000). Our results do not allow for inference on the possible direct effects of Aspergillus on wasp nest health. However, the potential presence of more Aspergillus species within both diseased larvae and mite samples, higher Aspergillus spp. and overall fungal loads in diseased compared to healthy larvaeincluding known entomopathogens such as Aspergillus and Metarhizium, suggests a strong association between wasps, mites and fungi. It is possible that Aspergillus and other pathogenic fungi might be exchanged between $P$. niutirani mites and wasps during feeding.

The feeding and biology of this mite and the potential association with pathogen transmission with wasps is poorly understood. Within the Pneumolaelaps mite genus, the best-known species is Pneumolaelaps longanalis. Hunter and Husband (1973) described how mites within beehives feed on both honey and pollen. However, the mites appeared to be very opportunistic and were observed to be highly attracted to and feed on bee haemolymph when bees were injured (Hunter and Husband 1973). These mites also appear highly attracted to larval food provisioning. Royce and Krantz (1989) observed $P$. longanalis to congregate in large numbers in brood cells. The mites occasionally appeared to feed on the larvae and their experiments indicated that sugar was highly attractive and an important feeding stimulus (Royce and Krantz 1989). Larvae of both Polistes and Vespula wasps, secrete droplets of sweet, carbohydraterich liquid to feed the adult wasps (Spradbery 1974). We have observed mites feeding on these secretions near the mouthparts of wasp larvae whose function is to feed many different adult wasps. Consequently, an orally transmitted disease could quickly be spread throughout a colony via both larvae-adult trophallactic feeding behaviour, and interaction between mites and wasp larvae. Alternatively, P. niutirani mites could infect larvae with pathogens by opportunistically feeding directly on wasp haemolymph, although this is behaviour is speculative as only reported in the closely related $P$. longanalis.
It is entirely possible that a high abundance of mites and the pathogens we discuss here are symptomatic of other undiscovered pathogens or environmental stressors. Our analysis, however, points to several pathogens that appear associated with mites and could be further investigated for biological control of invasive Vespula wasps. We primarily identified Moku virus heavily infecting mites, and the virus was also present in wasps. Six other putative viruses likely to infect arthropods were also shared between mites and wasps as well as a multitude of other viral-like transcripts, suggesting possible virus exchanges between the species. Furthermore, we found higher fungal diversity and fungal loads in diseased nests that were also shared with mites, including known entomopathogens such as Aspergillus spp. and Metarhizium. Overall, our results suggest that the study of pathogens potentially navigating between different hostshere the invasive wasps, $V$. germanica and $V$. vulgaris, and an associated mite Pneumolaelaps niutirani-is likely to improve screening for biological control agents. Our study also highlights the importance of studying pathospheres in order to gain insights on pathogen dynamics in wider biological systems.

Acknowledgements This work was supported by Victoria University of Wellington, and the Ministry of Business, Innovation and Employment (New Zealand's Biological Heritage NSC, C09X1501 \& Victoria University of Wellington, Internal grant). We thank Emily Remnant for useful discussions on viral discovery in RNA-Seq data, as well as two anonymous reviewers for their comments on the manuscript. No potential conflict of interest was reported by the authors.

Data accessibility Supplementary information, scripts and data can be downloaded from GitHub at https://doi.org/10.5281/zenodo.3484105; RNA-seq reads can be accessed on the NCBI SRA repository (BioProject ID PRJNA576756, http://www.ncbi.nlm.nih.gov/bioproject 1576756).

\section{References}

Andreadis TG (2007) Microsporidian parasites of mosquitoes. J Am Mosq Control Assoc 23:3-29. https://doi. org/10.2987/8756-971X(2007)23\%5b3:MPOM\%5d2.0.CO;2

Barlow ND, Beggs JR, Barron MC (2002) Dynamics of common wasps in New Zealand beech forests: a model with density dependence and weather. J Anim Ecol 71:663-671. https://doi.org/10.104 6/j.1365-2656.2002.00630.x

Buchfink B, Xie C, Huson DH (2015) Fast and sensitive protein alignment using DIAMOND. Nat Methods 12:59-60. https://doi. org/10.1038/nmeth.3176

Chen Y, Pettis JS, Evans JD, Kramer M, Feldlaufer MF (2004) Transmission of Kashmir bee virus by the ectoparasitic mite Varroa destructor. Apidologie 35:441-448. https://doi.org/10.1051/apido :2004031

de Miranda JR, Bailey L, Ball BV, Blanchard P, Budge GE, Chejanovsky N, Chen Y-P, Gauthier L, Genersch E, de Graaf DC, Ribière M, Ryabov E, Smet LD, van der Steen JJM (2013) Standard methods for virus research in Apis mellifera. J Apic Res 52:156. https://doi.org/10.3896/IBRA.1.52.4.22 
Dobelmann J, Loope KJ, Wilson-Rankin E, Quinn O, Baty JW, Gruber MAM, Lester PJ (2017) Fitness in invasive social wasps: the role of variation in viral load, immune response and paternity in predicting nest size and reproductive output. Oikos 126:1208-1218. https://doi.org/10.1111/oik.04117

Fan QH, Zhang ZQ, Brown R, France S, Bennett S (2016) New Zealand Pneumolaelaps (Acari: Laelapidae): description of a new species, key to species and notes on biology. Syst Appl Acarol 21:119-138. https://doi.org/10.11158/saa.21.1.8

Garigliany M, Agrebi NE, Franssen M, Hautier L, Saegerman C (2019) Moku virus detection in honey bees, Belgium, 2018. Transbound Emerg Dis 66:43-46. https://doi.org/10.1111/tbed.13055

Glare TR, Harris RJ, Donovan BJ (1996) Aspergillus flavus as a pathogen of wasps, Vespula spp., in New Zealand. N Z J Zool 23:339344. https://doi.org/10.1080/03014223.1996.9518093

Grozinger CM, Flenniken ML (2019) Bee viruses: ecology, pathogenicity, and impacts. Annu Rev Entomol 64:205-226. https:// doi.org/10.1146/annurev-ento-011118-111942

Gruber MAM, Cooling M, Baty JW, Buckley K, Friedlander A, Quinn O, Russell JFEJ, Sébastien A, Lester PJ (2017) Single-stranded RNA viruses infecting the invasive Argentine ant, Linepithema humile. Sci Rep 7:3304. https://doi.org/10.1038/s41598-01703508-z

Gruber MAM, Quinn O, Baty JW, Dobelmann J, Haywood J, Wenseleers T, Lester PJ (2019) Fitness and microbial networks of the common wasp, Vespula vulgaris (Hymenoptera: Vespidae), in its native and introduced ranges. Ecol Entomol. https://doi. org/10.1111/een.12732

Haas BJ, Papanicolaou A, Yassour M, Grabherr M, Blood PD, Bowden J, Couger MB, Eccles D, Li B, Lieber M, MacManes MD, Ott M, Orvis J, Pochet N, Strozzi F, Weeks N, Westerman R, William T, Dewey CN, Henschel R, LeDuc RD, Friedman N, Regev A (2013) De novo transcript sequence reconstruction from RNA-Seq: reference generation and analysis with Trinity. Nat Protoc. https://doi. org/10.1038/nprot.2013.084

Harris RJ, Harcourt SJ, Glare TR, Rose EAF, Nelson TJ (2000) Susceptibility of Vespula vulgaris (Hymenoptera: Vespidae) to generalist entomopathogenic fungi and their potential for wasp control. J Invertebr Pathol 75:251-258. https://doi.org/10.1006/ jipa. 2000.4928

Hay DB, Hart BJ, Douglas AE (1993) Effects of the fungus Aspergillus penicillioides on the house dust mite Dermatophagoides pteronyssinus: an experimental re-evaluation. Med Vet Entomol 7:271-274

Hunter PE, Husband RW (1973) Pneumolaelaps (Acarina: Laelapidae) mites from North America and Greenland. Fla Entomol 56:77-91. https://doi.org/10.2307/3493231

Kearse M, Moir R, Wilson A, Stones-Havas S, Cheung M, Sturrock S, Buxton S, Cooper A, Markowitz S, Duran C, Thierer T, Ashton B, Meintjes P, Drummond A (2012) Geneious Basic: an integrated and extendable desktop software platform for the organization and analysis of sequence data. Bioinformatics 28:1647-1649. https:// doi.org/10.1093/bioinformatics/bts199

Kim D, Langmead B, Salzberg SL (2015) HISAT: a fast spliced aligner with low memory requirements. Nat Methods 12:357-360. https ://doi.org/10.1038/nmeth.3317

Lester PJ, Beggs JR (2019) Invasion success and management strategies for social Vespula Wasps. Annu Rev Entomol 64:51-71. https ://doi.org/10.1146/annurev-ento-011118-111812

Lester PJ, Bosch PJ, Gruber MAM, Kapp EA, Peng L, Brenton-Rule EC, Buchanan J, Stanislawek WL, Archer M, Corley JC, Masciocchi M, Oystaeyen AV, Wenseleers T (2015) No evidence of enemy release in pathogen and microbial communities of common wasps (Vespula vulgaris) in their native and introduced range. PLoS One 10:e0121358. https://doi.org/10.1371/journal.pone.0121358

Lester PJ, Haywood J, Archer ME, Shortall CR (2017) The longterm population dynamics of common wasps in their native and invaded range. J Anim Ecol 86:337-347. https://doi. org/10.1111/1365-2656.12622

Levitt AL, Singh R, Cox-Foster DL, Rajotte E, Hoover K, Ostiguy N, Holmes EC (2013) Cross-species transmission of honey bee viruses in associated arthropods. Virus Res 176:232-240. https ://doi.org/10.1016/j.virusres.2013.06.013

Loope KJ, Baty JW, Lester PJ, Wilson-Rankin EE (2019) Pathogen shifts in a honeybee predator following the arrival of the Varroa mite. Proc R Soc B Biol Sci 286:20182499. https://doi. org/10.1098/rspb.2018.2499

MacIntyre P, Hellstrom J (2015) An evaluation of the costs of pest wasps (Vespula species) in New Zealand. Int Pest Control 57:162-163

McMenamin AJ, Brutscher LM, Glenny W, Flenniken ML (2016) Abiotic and biotic factors affecting the replication and pathogenicity of bee viruses. Curr Opin Insect Sci 16:14-21. https:// doi.org/10.1016/j.cois.2016.04.009

Mordecai GJ, Brettell LE, Pachori P, Villalobos EM, Martin SJ, Jones IM, Schroeder DC (2016) Moku virus; a new Iflavirus found in wasps, honey bees and Varroa. Sci Rep 6:34983. https ://doi.org/10.1038/srep34983

Pertea M, Pertea GM, Antonescu CM, Chang T-C, Mendell JT, Salzberg SL (2015) StringTie enables improved reconstruction of a transcriptome from RNA-seq reads. Nat Biotechnol 33:290295. https://doi.org/10.1038/nbt.3122

Quinn O, Gruber MAM, Brown RL, Baty JW, Bulgarella M, Lester PJ (2018) A metatranscriptomic analysis of diseased social wasps (Vespula vulgaris) for pathogens, with an experimental infection of larvae and nests. PLoS One. https://doi.org/10.1371/ journal.pone.0209589

Rigaud T, Perrot-Minnot M-J, Brown MJF (2010) Parasite and host assemblages: embracing the reality will improve our knowledge of parasite transmission and virulence. Proc R Soc B Biol Sci 277:3693-3702. https://doi.org/10.1098/rspb.2010.1163

Roberts A, Pachter L (2012) Streaming fragment assignment for realtime analysis of sequencing experiments. Nat Methods 10:71. https://doi.org/10.1038/nmeth.2251

Robinson MD, McCarthy DJ, Smyth GK (2010) edgeR: a bioconductor package for differential expression analysis of digital gene expression data. Bioinformatics 26:139-140. https://doi. org/10.1093/bioinformatics/btp616

Rose EAF, Harris RJ, Glare TR (1999) Possible pathogens of social wasps (Hymenoptera: Vespidae) and their potential as biological control agents. N Z J Zool 26:179-190. https://doi. org/10.1080/03014223.1999.9518188

Royce LA, Krantz GW (1989) Observations on pollen processing by Pneumolaelaps longanalis (Acari: Laelapidae), a mite associate of bumblebees. Exp Appl Acarol 7:161-165. https://doi. org/10.1007/BF01270436

Santamaria J, Villalobos EM, Brettell LE, Nikaido S, Graham JR, Martin S (2018) Evidence of Varroa-mediated Deformed wing virus spillover in Hawaii. J Invertebr Pathol 151:126-130. https ://doi.org/10.1016/j.jip.2017.11.008

Schwarz RS, Huang Q, Evans JD (2015) Hologenome theory and the honey bee pathosphere. Curr Opin Insect Sci 10:1-7. https ://doi.org/10.1016/j.cois.2015.04.006

Sébastien A, Lester PJ, Hall RJ, Wang J, Moore NE, Gruber MAM (2015) Invasive ants carry novel viruses in their new range and form reservoirs for a honeybee pathogen. Biol Let 11:20150610. https://doi.org/10.1098/rsbl.2015.0610

Solter LF, Becnel JJ, Oi DH (2012) Microsporidian entomopathogens. In: Vega FE, Kaya HK (eds) Insect pathology, chapter 7, 2nd edn. Academic Press, San Diego, pp 221-263. https://doi. org/10.1016/B978-0-12-384984-7.00007-5 
Spradbery P (1974) wasps. an account of the biology and natural history of solitary and social wasps. Q Rev Biol 49:159. https://doi. org/10.1086/408041

St. Leger RJ, Screen SE, Shams-Pirzadeh B (2000) Lack of host specialization in Aspergillus flavus. Appl Environ Microbiol 66:320-324
Yue C, Genersch E (2005) RT-PCR analysis of Deformed wing virus in honeybees (Apis mellifera) and mites (Varroa destructor). J Gen Virol 86:3419-3424. https://doi.org/10.1099/vir.0.81401-0 